\title{
A nova gestão pública no contexto da educação pernambucana e a qualidade educacional ${ }^{1}$
}

\author{
The new public management in the context of education in pernambuco and the \\ quality of education
}

\section{La nueva gestión pública en el contexto de la educación y pernambucana y la calidad educativa}

\section{LUCIANA ROSA MARQUES JULIANA CAMILA BARBOSA MENDES IÁGRICI MARIA DE LIMA MARANHÃO}

\begin{abstract}
Resumo: O artigo objetiva trabalhar as repercussões da Nova Gestão Pública na gestão da educação, tendo como foco a qualidade educacional. Faz uma discussão sobre NGP e sua materialização no contexto educacional, identificando os elementos discursivos que compõe a qualidade. Analisa a política educacional pernambucana, a partir de documentos e entrevistas com gestores escolares, visando compreender que sentido de qualidade se coloca como hegemônico. Verificou posições conflituosas que constituem o discurso, atravessado pela regulação dos parâmetros de desempenho e pela qualidade socialmente referenciada.
\end{abstract}

Palavras-chave: Nova Gestão Pública; Qualidade da Educação; Teoria do Discurso; Pernambuco.

\begin{abstract}
The article aims to work the repercussions of the New Public Management in the management of education, focusing on the quality of education. It makes a discussion about NGP and its materialization in the educational context, identifying the discursive elements that compose the quality. It analyzes the education policy of Pernambuco, based on documents and interviews with school managers, in order to understand the meaning of quality as hegemonic. It was verified conflicting positions that constitute the discourse, crossed by the regulation of performance parameters and socially referenced quality.
\end{abstract}

Keywords: New Public Management; Quality of Education; Discourse Theory; Pernambuco.

Resumen: El artículo pretende trabajar las repercusiones de la Nueva Gestión Pública en la gestión de la educación, centrándose en la calidad educativa. Realiza un debate sobre la NGP y su materialización en el contexto educativo, identificando los elementos discursivos que componen la calidad. Analiza la política educativa de Pernambuco, a partir de documentos y entrevistas 
con gestores escolares, buscando comprender qué sentido de calidad se pone como hegemónico. Verificó posiciones conflictivas que constituyen el discurso, atravesado por la regulación de los parámetros de desempeño y por la calidad socialmente referenciada.

Palabras clave: Nueva Gestión Pública; Calidad de la Educación; Teoría del Discurso; Pernambuco.

\section{INTRODUÇÃO}

A Nova Gestão Pública (NGP) se tem colocado como paradigma dominante de gestão da coisa pública na atualidade. Embora sem um formato fixo e definido, baseia-se nos preceitos da gestão empresarial, que são utilizados como parâmetros de eficácia e eficiência e que devem ser implantados no setor público. Para o CLAD (Conselho Latino-Americano para o Desenvolvimento) a implantação da NGP na região deve atender às seguintes particularidades:

- Profissionalização da alta burocracia;

- Transparência e responsabilização;

- Descentralização na execução de serviços públicos;

- Desconcentração organizacional nas atividades exclusivas do Estado;

- Controle dos resultados;

- Novas formas de controle;

- Duas formas de unidades administrativas autônomas: agências que realizam atividades exclusivas do Estado e agências descentralizadas, que atuam nos serviços sociais e científicos;

- Orientação da prestação de serviços para o cidadão usuário;

- Modificação do papel da burocracia com relação à democratização do poder público.

De forma geral, a Nova Gestão Pública pode ser definida como um programa de reforma do setor público com base em instrumentos da gestão empresarial, que visa a melhorar a eficiência e eficácia dos serviços públicos nas burocracias modernas.

É importante salientar que a NGP não adota a perspectiva de retirada do Estado para ampliação da dominação capitalista, mas de sua reconstrução. Assim, passa-se da ideia de "Estado Mínimo" para a de "Estado Melhor", que também seria uma esfera regida pelas regras da concorrência e submetida às exigências de eficácia semelhantes às da empresa privada. Adota, portanto, a lógica do setor privado, que deve ser referência para o público, tornando o modelo empresarial universalmente válido para pensar a ação pública e social. 
No entanto, de acordo com Dasso Júnior (2014, p. 16) “inspirar-se na gestão privada é um erro conceitual grave porque a gestão pública é, pelos fins e meios, absolutamente diferente da gestão privada". Para ele, enquanto a lógica do público deve ser inspirada na solidariedade, nos interesses coletivos, no cidadão, a lógica privada é determinada pela lógica mercantil do consumo, dos interesses individuais, do cliente, tratando-se, portanto, de duas lógicas antagônicas.

Objetiva-se a constituição do 'Estado Gerencial', que é reestruturado externamente com privatizações, que põe fim ao 'Estado Produtor', mas também internamente, com a instauração de um Estado avaliador e regulador, que constitui novas relações entre governo e sujeitos sociais.

Essa vontade de impor no cerne da ação pública os valores, as práticas e o
funcionamento da empresa privada conduz à instituição de uma nova prática de
governo. Desde os anos 1980, o novo paradigma em todos os países da OCDE
determina que o Estado seja mais flexível, reativo, fundamentado no mercado e
orientado para o consumidor. O management apresenta-se como um modelo de
gestão 'genérico', válido para todos os domínios, como uma atividade puramente
instrumental e formal, transponível para todo o setor público. Essa mutação
empresarial não visa apenas a aumentar a eficácia e a reduzir os custos da ação
pública; ela subverte radicalmente os fundamentos modernos da democracia, isto
é, o reconhecimento de direitos sociais ligados a status de cidadão (DARDOT;
LAVAL, 2016 p. 274).

Esse movimento que se vem constituindo como hegemônico em torno do globo, também se vem consolidando no Estado brasileiro, a nível nacional, estadual e municipal, tendo como principais características a redução do aparelho estatal, privatização, cortes, redução do funcionalismo, além da implantação das parcerias público-privado, em seus diferentes formatos. Temos, assim, vivenciado a consolidação do "Estado Gerencial" em nosso país.

\section{A NOVA GESTÃO PÚBLICA NO CONTEXTO DA EDUCAÇÃO}

A Nova Gestão Pública vem penetrando com força a agenda educativa global, tanto em países industrializados como nos em via de desenvolvimento, alterando a forma como se concebe a gestão de instituições educativas, já que princípios como autonomia escolar, prestação de contas e gestão baseada em resultados têm norteado a forma como se regula, provê e financia a educação pública.

A NGP não é um modelo de reforma educacional monolítico nem adota o mesmo formato em todos os países, sendo possível observar enfoques de gestão e desenhos de política educacional bem diferenciados e se tem constituído como 
um novo paradigma de políticas que dota os fazedores de política de categorias e modelos de marcos interpretativos nas decisões da política educacional, visando à qualidade da educação. Suas políticas podem ser consideradas, portanto, um significante flutuante ${ }^{2}$ (LACLAU; MOUFFE, 1985). Segundo Verger (2015), as soluções da NPG não são adotadas porque funcionam, mas porque existe uma percepção generalizada de que são políticas que poderiam solucionar os problemas mais importantes dos sistemas educativos contemporâneos, sendo adotadas tanto por governos do campo conservador, quanto do progressista ${ }^{3}$.

Os princípios da NGP transpostos à educação, cristalizam-se em um amplo leque de políticas, sistematizados por Verger (2015) no quadro a seguir:

\begin{tabular}{|c|c|}
\hline PRINCÍPIOS NPG & POLÍTICAS EDUCACIONAIS \\
\hline Gestão profissional dos serviços públicos & $\begin{array}{l}\text { Profissionalização e empoderamento dos gestores } \\
\text { escolares }\end{array}$ \\
\hline Normas e medidas de desempenho mais explícitas & $\begin{array}{l}\text { - Definição de indicadores de qualidade e de } \\
\text { benchmarks sobre êxito educativo } \\
\text { - Padrões curriculares comuns }\end{array}$ \\
\hline Ênfase no controle dos resultados & $\begin{array}{c}\text { Avaliação externa dos resultados e do rendimento } \\
\text { escolar }\end{array}$ \\
\hline $\begin{array}{l}\text { Desagregar o setor público em pequenas unidades de } \\
\text { gestão }\end{array}$ & Autonomia escolar, school-based management \\
\hline Maior competição no setor público & $\begin{array}{l}\text { - Subsídios públicos para as escolas privadas } \\
\text { - Financiamento per cápita } \\
\text { - Publicação dos resultados obtidos pelas escolas em } \\
\text { testes estandardizados }\end{array}$ \\
\hline Adotar o estilo gerencial do setor privado & $\begin{array}{l}\text { - Flexibilização de contratação e dispensa pela escola } \\
\text { - Estilo gerencial para direçẫo das escolas }\end{array}$ \\
\hline Restrição no uso de recursos públicos & $\begin{array}{l}\text { - Financiamento das escolas com base nos resultados } \\
\text { - Remuneração dos docentes com base em critérios de } \\
\text { mérito e produtividade }\end{array}$ \\
\hline
\end{tabular}

Um dos mais expressivos efeitos da NGP na educação é a adoção da "cultura dos resultados". Assim, a definição de indicadores de eficiência que visam a aferir a qualidade educacional têm sidos colocados, cada vez mais, como elementos de qualificação da educação. Esse movimento se alinha à nova racionalidade administrativa, calcada na lógica empresarial e no pressuposto da NPG de que os agentes públicos devem procurar maximizar os resultados, respeitando as expectativas do cliente.

2 Quando um significante desliza entre diferentes processos de significação, sendo identificado de maneiras distintas, catalisando sentidos de grupos específicos do conjunto da heterogeneidade social, mas simultaneamente não assumindo a condição de representante do todo, ele passa a ser concebido como um significante flutuante, sendo vinculado a diversos sentidos específicos.

3 Para Dardor e Laval (2016) essa reinvenção do governo se apresenta com frequência como uma invenção da política de esquerda, expressando a dominação da nova razão neoliberal. 
A técnica de gestão se baseia no tripé objetivos-avaliação-sanção (ou recompensa) e as unidades passam a ser responsáveis por seus resultados (accountability), recebendo metas que devem atingir, que são avaliadas regularmente, sendo sancionadas positiva ou negativamente de acordo com seu desempenho. A NPG constrói, assim, um 'novo sujeito', cuja conduta é guiada pelos processos avaliativos e sancionários, interiorizando normas de desempenho e autovigilância, para se adequar aos indicadores e à competição com os outros.

Para Dardort e Laval (2016, p. 313)

A questão é saber o que dizer da "cultura de resultado" na justiça, na medicina, na cultura ou na educação e sobre quais valores podemos julgá-la. Na verdade, o ato de julgamento, que depende de critérios éticos e políticos, é substituído por uma medida de eficiência que se supõe ideologicamente neutra. Assim, tende-se a ocultar as finalidades próprias de cada instituição em benefício de uma norma contábil idêntica, como se cada instituição não tivesse valores constitutivos que lhe são próprios.

Para os autores, além da ênfase no desempenho há a importação do critério de qualidade utilizado no campo empresarial. Assim, a NPG teria como objetivo transformar as instituições públicas tradicionais em organizações voltadas para o desempenho, dando maior satisfação ao cliente, que escolherá livremente o prestador de serviço. Essa “gestão por desempenho' faz parte de uma espécie de 'desfuncionalização' do serviço público” (DARDORT e LAVAL, 2016, p. 305). Nessa perspectiva o sentido de qualidade se traduz em bons resultados em avaliações quantitativas, que, no Brasil, foi um dos principais instrumentos para adaptação do sistema educacional à nova ordem global, integrando-se ao movimento da Reforma do Estado, baseada nos preceitos da NGP.

No entanto há que se considerar o caráter polissêmico da qualidade educacional, tendo em vista "que a concepção de mundo, de sociedade e de educação evidencia e define elementos para qualificar, avaliar e precisar a natureza, as propriedades e os atributos desejáveis de um processo educativo de qualidade social" (DOURADO; OLIVEIRA, 2009, p. 202). Assim, embora a educação de qualidade na atualidade possa ser considerada como um ponto nodal ${ }^{4}$, seus sentidos são diferenciados. Dessa forma, pode-se falar em qualidades da educação, a depender da perspectiva teórica e do projeto social em que se inserem os que dela estão falando.

4 Segundo Mouffe (1996), toda construção política tem sempre lugar contra um conjunto de práticas sedimentadas e o campo do social poderia ser visto como uma disputa entre diferentes projetos que tentam fixar significados em torno de um ponto nodal (fixações parciais que limitam o fluxo do significado sobre o significante), tornando-se, dessa forma, hegemônico. 
Diante disto, a qualidade deve ser compreendida em sua perspectiva histórica, alterando-se, portanto, no tempo e no espaço, pois o conceito de qualidade se vincula às demandas e exigências sociais de um dado processo histórico. Destarte,

Caso se tome como referência o momento atual, tal perspectiva implica compreender que embates e visões de mundo se apresentam no cenário atual de reforma do estado, de rediscussão dos marcos da educação - como direito social e como mercadoria -, entre outros. (DOURADO; OLIVEIRA, 2009, p. 201)

Tomando por base essa compreensão, deve-se destacar que, no Brasil, até a década de 1980, o debate educacional se dava em torno do acesso à escola pela maioria da população. A partir de então, o foco dos problemas educacionais passa a ser a permanência e o percurso com sucesso da escolarização de crianças, jovens e adultos. Toma vulto, então, a discussão da qualidade na educação, que se desenvolve sob dois enfoques antagônicos: o da qualidade total e o da qualidade social.

De acordo com Ball (2006), a formulação da qualidade na educação está relacionada ao debate mais amplo nas sociedades ocidentais, em particular por conta de sua inserção na retórica advinda do mundo econômico, de onde emerge associada ao conceito de qualidade total, cujos enunciados passam a ser - educação de resultados, flexibilidade e empreendedorismo nos currículos educacionais uma gramática singular que dá relevo a enunciados de excelência, efetividade e qualidade, regidos pela lógica da cultura do gerencialismo. Ainda segundo o autor, no debate que se instala, outros enunciados no âmbito do discurso da qualidade educacional surgem, outra retórica sob a qual o conceito de qualidade social aparece associado às temáticas da justiça social, inclusão social e cultural.

Pode-se afirmar que não há “uma educação de qualidade em si, mas tantas educações de qualidade quantas sejam as que os grupos sociais possam enunciar, conhecer, pensar discutir, disputar. Tantas educações de qualidade quantas houver condições de descrever" (FUNDAJ, 2009). Importa, portanto, assegurar a consistência dessa postura evitando-se restringir a qualidade da Educação Básica tão somente a resultados de produtos. Para Oliveira (2007), os resultados constituem uma das dimensões da qualidade da educação que deve ser buscada, constituindo uma contribuição importante para apreender progressos, identificar problemas e lacunas, orientar a definição de ações, mas, além dos resultados, é preciso contemplar duas outras dimensões, a do insumo, redenominada condições 
objetivas em que se realiza a educação escolar, e a do processo escolar como tal. Para ele, "cabe, pois, criar as condições de efetivação do princípio constitucional do padrão de qualidade do ensino como nova dimensão do direito à educação" (p. 21).

Nesse contexto, pesquisadores da educação têm despendido esforços para compreender e analisar as mudanças ocorridas a partir da década de 1980 e denunciar os riscos que as políticas implementadas sob a égide da modernização conservadora trazem para a democratização da educação, um direito humano e um bem público, potencialmente emancipatório, de responsabilidade do Estado (COSTA, 2019).

É nesta perspectiva que se insere este trabalho, que analisa as repercussões da implantação de um modelo de gestão estatal baseado na NPG no sentido de qualidade educacional. Foi estudado o caso de Pernambuco, estado que se vem destacando nos resultados das avaliações em larga escala adotadas no país. Para tal, analisamos o Programa de Modernização da Gestão Pública - Metas para Educação (PMGPE/ME) e entrevistamos gestores de escolas da rede estadual de ensino.

Os dados foram trabalhados a partir dos aportes teóricos da Teoria do Discurso de Erneto Laclau e seus seguidores, que está fundada na ideia de que o social deve ser percebido a partir da lógica do discurso.

Discurso que, por sua vez não deve ser entendido como simples reflexo de
conjuntos de textos. Discurso é uma categoria que une palavras e ações, que tem
natureza material e não mental e/ou ideal. Discurso é prática - daí a noção de prática
discursiva - uma vez que quaisquer ações empreendidas por sujeitos, identidades,
grupos sociais são ações significativas. O social, portanto, é um social significativo,
hermenêutico. Não aparece como algo a ser simplesmente desvendado, desvelado,
mas compreendido, a partir de sua miríade de formas, das várias possibilidades de
se alcançarem múltiplas verdades, note-se, sempre contingentes e precárias. Assim,
a realidade, como possibilidade de ser perscrutada, conhecida verdadeiramente, é
uma impossibilidade, tendo em vista que esta é significada de diversas maneiras, a
partir de diferentes estruturas discursivas. (MENDONÇA; RODRIGUES, 2014,
p. 49).

A análise de uma prática discursiva focaliza os processos de produção, consumo e mudança textual, o que exige referência aos ambientes econômicos, políticos e institucionais particulares nos quais o discurso é gerado. Dessa forma, todas as configurações sociais são significativas e os significados das palavras e práticas dependem do espaço discursivo, que é construído por práticas 
articulatórias 5 , em que se colocam. Enquanto prática social, o discurso é tomado como prática política, que transforma, mantém e estabelece as relações de poder e as entidades coletivas em que tais relações se colocam, havendo, portanto, uma competição para fixar sentidos ${ }^{6}$ a configurações significativas particulares.

Essa perspectiva de análise do discurso abre a possibilidade para reativação da origem política contingente do que é fixado e objetivamente apresentado, abrindo espaço para novos antagonismos e fixação de novos conteúdos e formas que não se colocavam até então, tornando possível, assim, a articulação de uma multiplicidade de discursos concorrentes e, consequentemente, da transformação dos agentes e práticas sociais. Assim, a prática de articulação, como deslocamento / fixação de um sistema de diferenças penetra a densidade inteiramente material da multiplicidade de instituições, rituais e práticas através das quais uma estrutura discursiva é estruturada (LACLAU; MOUFFE, 1985). Dessa forma, a prática discursiva tanto pode contribuir para a reprodução da sociedade, como para sua transformação.

\section{NOVA GESTÃO PÚBLICA, POLÍTICA EDUCACIONAL E QUALIDADE EM PERNAMBUCO}

O modelo gestor do Estado de Pernambuco foi implementado em 2003 pelo então governador Jarbas Vasconcelos, tendo continuidade nos governos posteriores, especialmente no de Eduardo Campos, quando foi solidificado com a implantação do Programa de Modernização da Gestão Pública do Estado (PMGPE). Eduardo Campos em seu discurso de posse aponta que a pretensão seria de desenvolver um modelo de gestão pública com o lema 'Integrar para desenvolver', em que as questões levantadas no ano anterior na produção da plataforma de governo, tornam-se elementos para reflexão sobre as possíveis ações que viriam.

O modelo de gestão pública adotado reúne aspectos gerenciais reorganizados no que se denominou planejamento gestor, rompendo com os modelos anteriores e estabelecendo a modernização em vários aspectos, construindo um modelo integrado de gestão, que sugere ter sido criado em consonância com os anseios da população. $\mathrm{O}$ discurso do governo aponta para

5 Para Laclau, uma estrutura discursiva não é uma entidade meramente "cognitiva" ou "contemplativa"; é uma prática articulatória que constitui e organiza as relações sociais. Uma prática articulatória consiste na "construção de pontos nodais - "fixações parciais que limitam o fluxo entre significado e significante" (MOUFFE, 1996, p.103) - que fixam parcialmente sentido; o caráter parcial dessa fixação procede da abertura do social, resultante, por sua vez, de um constante transbordamento de todo discurso pela infinitude do campo da discursividade" (LACLAU; MOUFFE, 1985, p. 113). 
a evolução do Estado que num curto espaço de tempo, levaria Pernambuco a apresentar um novo modelo de gestão pública como o eixo de mudanças radicais, que estabeleceria indicadores que seriam utilizados para referendar a qualidade dos serviços públicos, com especial destaque para a educação, saúde e segurança pública.

Especificamente para a educação, o PMGPE estabelece um novo panorama, apresentando uma gestão por resultados e dispondo metas para a educação, voltadas para o desenvolvimento do sistema educacional do estado, surgindo, assim, o Programa de Modernização da Gestão Pública/Metas para educação, que se apresenta como resposta aos baixos índices de desempenho no IDEB de Pernambuco - "o pior IDEB Brasil no ensino fundamental de $5^{\mathrm{a}}$ a $8^{a}$ série $(2,4)$ " - estabelecendo como meta alcançar a média de seis pontos $(6,0)$ no IDEB até 2021 (PERNAMBUCO, 2008; 2012, p.5)

Cabe ao Programa de Modernização da Gestão, como um plano maior que abarca a política educacional, a intencionalidade de "melhoria dos indicadores educacionais do estado, trabalhando a gestão por resultados". Este programa foi desenvolvido em parceria com o Movimento Brasil Competitivo (MBC) e o Instituto de Desenvolvimento Gerencial (INDG) e está baseado na tríade: diagnóstico, planejamento e gestão.

O Governo de Pernambuco avança na melhoria dos indicadores educacionais através da implantação do Projeto de Modernização da Gestão Pública já a partir de 2008. O evento de lançamento aconteceu, no dia 12 de dezembro de 2007, no centro de convenções de Olinda, com a presença de professores e gestores da rede pública. A ideia é tornar Pernambuco uma referência nacional em Educação até 2011. Com o projeto, todos os profissionais das escolas que alcançarem as metas propostas no termo de compromisso - assinado em janeiro entre a Secretaria e os gestores serão premiados com um $14^{\circ}$ salário ao final de cada ano. A ação é consequência do convênio assinado em maio de 2007 entre o governador Eduardo Campos e o empresário Jorge Gerdau, do Movimento Brasil Competitivo, com apoio técnico do Instituto de Desenvolvimento Gerencial (INDG). (PERNAMBUCO, 2011, p.12)

O engendramento dessa política se dá via assinatura de um Termo de Compromisso entre a equipe gestora da unidade escolar e a Secretaria Estadual de Educação, visando à elevação dos indicadores educacionais, e, para isso, definindo as metas de desempenho institucional a serem alcançadas no ano. Também ficam estabelecidas através do termo, as obrigações para ambas as partes, a "Secretaria de Educação deve apoiar a escola na elaboração e na implementação de sua Proposta Pedagógica, oferecendo a infraestrutura necessária e desenvolvendo ações que garantam a presença de professores em todas as suas turmas e disciplinas" e a "equipe gestora fica responsável pela elaboração e execução de seu Plano de Ação”, (PERNAMBUCO, 2012, p. 44) este último com atribuições específicas 
sobre a matriz curricular, calendário escolar, ações de apoio ao estudante no que diz respeito ao acesso, à permanência e ao atendimento ao Censo Escolar, que apura os índices anuais de aprovação, reprovação e abandono.

No entanto, segundo os diretores entrevistados, os compromissos da secretaria são bastante genéricos, como garantir professores, dar formações, compromissos institucionais, que a secretaria de educação tem o dever de garantir. O compromisso principal é das escolas que têm que identificar suas dificuldades para melhorar as notas. "Esse é o único compromisso que a escola tem que ter! [...] São várias ações, mas que na verdade, visam só os índices melhorarem” (Diretor 01).

$\mathrm{Na}$ formulação do termo de compromisso são fixadas metas para o IDEPE que é seu indicador central. O cálculo do IDEPE utiliza os mesmos procedimentos estabelecidos pelo Ministério da Educação para o IDEB. O índice considera os resultados do Sistema de Avaliação da Educação Básica de Pernambuco (SAEPE) para avaliar o desempenho dos estudantes da rede: a média do desempenho dos estudantes em Língua Portuguesa e Matemática; e o fluxo escolar, que representa a progressão dos estudantes. Portanto, cada escola possuirá sua própria meta, de acordo com os resultados no SAEPE. O SAEPE e IDEPE são instrumentos utilizados com o propósito de medir anualmente a qualidade da educação na rede de ensino público do estado e os resultados servem como diagnóstico e parâmetro de desempenho para o sistema de educação de Pernambuco, bem como requisito para instituir o Bônus de Desempenho Educacional (BDE).

O modelo de gestão adotado no estado de Pernambuco na educação baseia-se em metas e no compromisso de seguir diretrizes pautadas em resultados de avaliação de desempenho e de rendimento dos estudantes, visando a investimentos pela ordem da eficácia das políticas públicas, com base no "Estado do Controle" e no "Estado do Fazer" como expresso no artigo $2^{\circ}, \mathbb{\int} 1^{\circ}$, inciso I da Lei $\mathrm{n}^{\circ}$ 15.377, que estabelece as diretrizes orçamentárias do estado de Pernambuco:

I - O ESTADO DO FAZER - CAPACIDADE DE GERAR RESULTADOS PARA TODOS OS PERNAMBUCANOS. Perspectiva voltada para a modernização e eficientização da gestão pública estadual, com foco na racionalização dos recursos e otimização dos resultados, seguindo um modelo de governança democrático, transparente e eficiente, que investe em tecnologia de gestão com reconhecimento do papel do capital humano como diferencial na qualidade, mantendo o equilíbrio fiscal entre receitas e despesas, permitindo que o Estado invista todo o seu potencial a favor da sociedade e do desenvolvimento. (PERNAMBUCO, 2014) 
O modelo de gestão almejado por Pernambuco incorpora uma perspectiva de gerir que compreende adoção da meritocracia e mecanismos de controle social, sendo esses os pontos centrais incorporados ao modo de gerir. O Estado do controle é equiparado ao Estado do fazer, 'o Estado eficiente e o Estado cidadão', quando este incorpora, na mesma medida, qualidade, modernização, responsabilização e accountability. Os esforços denotam a construção e de um modelo de governança para resultados, implementado pelo governo do Estado, que fundamentou as ações desenvolvidas nas áreas temáticas ou estratégicas de forma interligada, sendo essa a nova face da gestão pública que pressupõe a boa governança.

A premissa desse modelo está centrada no ciclo de gestão que busca identificar demandas e expectativas da sociedade (origem) e tem por fim prestar de contas sobre resultados ao cidadão (destino). Portanto, desde 2006, ocorre uma transição do paradigma de reforma do Estado que, em governos anteriores, buscou a racionalização e redução dos gastos públicos, como por exemplo, na transferência de prestação de serviços públicos para Organizações Sociais (OS), e também a privatização de empresas estatais. Agora, a administração pública assume o foco na gestão de resultados e o Modelo de Gestão Todos por Pernambuco é totalmente alinhado aos princípios da NGP.

A qualidade assume centralidade no PMGE-Metas pela Educação, tendo como sentido prevalente a melhoria dos resultados nas avaliações de larga escala. Os objetivos estratégicos da educação são planejados e executados através da metodologia de pacto de resultados, que teriam por finalidade obter a melhoria em indicadores de qualidade dos serviços públicos. A meritocracia no serviço público atravessa todas as categorias e mais especificamente a definição de qualidade nessa política. Essa construção discursiva de 'melhoria' e de 'soluções' para o campo educacional, evoca uma dimensão de 'resgate' da qualidade, que poderia remeter a uma ideia de que este seja um referencial perdido.

A modernização, através do modelo de gestão com foco em resultados, é compreendida como o meio mais eficaz para o estado alcançar melhores indicadores sociais na educação, diminuindo as taxas de repetência e evasão escolar, de analfabetismo e, sobretudo, proporcionar uma educação de qualidade às crianças e jovens pernambucanos, onde todos tenham o direito a aprender.

Para além de da compreensão de qualidade a partir de padrões de desempenho, o sentido de qualidade também é definido como inclusão e cidadania. Essa percepção é construída a partir da oferta de educação pública de qualidade focada em resultados, uma vez assegurada por meio de uma política de Estado, que visa a garantir acesso, permanência e formação plena do estudante, sendo, assim, pautada nos princípios de inclusão e cidadania. 
Do mesmo modo, a significação de educação de qualidade como direito advém desse tipo de construção retórica. Assim, o papel da secretaria de educação (SE) está designado em formular e coordenar a implementação das políticas públicas educacionais, apoiando as escolas no desenvolvimento de seu projeto pedagógico e avaliando os resultados obtidos e verificando se os direitos dos estudantes por uma educação de qualidade estão sendo respeitados. O modelo de gestão por resultados estabelece um novo paradigma para o sistema de ensino estadual, propondo "ofertar uma educação pública de qualidade social como direito fundamental de todas as pessoas, fundamentada no respeito aos direitos humanos, na equidade, na relevância, na pertinência, na eficácia e na eficiência" (PERNAMBUCO, 2012, p. 6). Assim, qualidade social se articula aos princípios de direito, relevância, pertinência, eficácia e eficiência, prevendo a adequação das escolas a padrões básicos de qualidade.

No entanto, apesar da afirmação do direito a uma educação de qualidade nos documentos oficiais, percebemos que os sujeitos "absorvem o discurso" da modernização dando mais força ao movimento proposto pelo governo, consolidado enquanto uma prática social, sem, no entanto, perder a dimensão crítica ao modelo implantado, como apontam os fragmentos das falas de alguns gestores entrevistados.

\footnotetext{
"Qualidade da educação hoje pode ser definida sob muitos aspectos. Mas é inegável que vivenciamos a era dos índices e eles que ditam o que é de qualidade e o que não é. Podemos trazer, na nossa prática, um conceito diferente e inserir outros elementos que não são contabilizados no IDEB ou no IDEPE [...] mas que estão lá e que são fundamentais no processo de construção desses resultados. Já para o governo, acho que a qualidade é expressa pelos números e nenhum outro elemento mais. Para isso basta ver a cultura de monitoramento" (Gestor 06)

\begin{abstract}
"Quando não tínhamos IDEB, o que definia a qualidade da educação? Da escola? Não havia nenhum modelo de avaliação e nunca se pensou na importância de que pudéssemos ter algo que definisse uma educação de qualidade. Não por acaso isso pode ter dois vieses: um de caráter economicista e mercantilista voltado para atender um panorama externo - vejam, a gente atende ao modelo de avaliação da OCDE que atende ao sistema econômico. Não é por acaso que as mudanças passem a ser em torno de metas e resultados, baseados num sistema gerencialista que não tem muito nada com nada, com a educação" (Gestor 08)
\end{abstract}

Nessa relação, avaliação e qualidade, encontra-se uma convocação pública como marco figurativo em que o sistema de avaliação educacional de Pernambuco e as metas para a Educação Básica constituem uma política pública cuja diretriz é assegurar a melhoria da qualidade da educação pública. Isto requer o comprometimento de todos: professores, gestores, estudantes e suas famílias, unidos no esforço de cumprimento das metas estipuladas. 
O alinhamento dos discursos entre as mais diversas esferas governamentais, expressa uma homogeneização das práticas discursivas, da forma como Vieira; Ferraz (2012) apresentam como exemplo da tecnologização do discurso. Ou seja, os governos compreenderam o que podem provocar utilizando um discurso que tenha como finalidade orientar o que o projeto de Estado almeja. Apreendendo isso de forma tangível, podemos perceber termos utilizados nas falas dos gestores, como: desafios, mudanças, resultados, positivos, qualidade, comportamento, entre outros, remetendo à incorporação de um discurso do campo privado.

\section{CONSIDERAÇÕES FINAIS}

Na política educacional pernambucana, materializada no PMGPE/Metas para educação, observa-se que os princípios da NPG são hegemônicos em seu texto. Centralidade das avaliações, gestão por metas e resultados, profissionalização da gestão, competitividade, padronização curricular, parceria com instituições do setor privado constituem-se como seus elementos fulcrais. Está sedimentado, portanto, um dos principais objetivos da NGP de transformar as administrações públicas tradicionais em organizações voltadas para o desempenho.

Pernambuco assume o compromisso de dinamizar os serviços públicos tornando-os mais eficientes e eficazes, comprometendo-se com o uso do dinheiro público e com o atendimento de qualidade aos cidadãos, a partir da implantação do Programa de Modernização da Gestão no Estado. Essa arena política gera um novo conceito de qualidade que se caracteriza pelo estabelecimento de metas e resultados. Assim, perceber essas reformas como uma necessidade de repensar o papel do Estado aportando-se no discurso de que este deveria oferecer serviços de qualidade se apresenta enquanto um desafio para a área educacional.

O desafio se constitui mediante as transformações nos modelos organizacionais em todas as repartições públicas levando à criação de vários programas tendo como finalidade a dinamização da gestão pública. Na educação, o PMGPE/Metas para educação surge apresentando como objetivo assegurar a qualidade da educação pública, por meio de uma política de Estado que redefina os parâmetros de gestão escolar.

Ao mesmo tempo, o PMGPE/Metas para educação aponta para a implantação de uma educação pública de qualidade que visa a garantir o acesso, a permanência e a formação plena do aluno, pautada na inclusão e na cidadania, além de consolidar nas unidades de ensino a cultura da democracia e da participação popular, deixando evidentes as contradições que permeiam o discurso de qualidade na rede estadual pernambucana. 
As metas são centrais e se vêm solidificando discursivamente, mas o próprio texto da política apresenta elementos da qualidade em uma perspectiva socialmente referenciada. O discurso da qualidade apresenta, assim, elementos de perspectivas teóricas distintas, que não se colocam como antagônicas, mas, sim, de forma complementar. Desse modo a qualidade anunciada na política estadual pertence a um repertório de posições conflituosas que constituem os sujeitos desse discurso, atravessado pela regulação dos parâmetros de desempenho, apresentando um problema para o pretendido fechamento no interior do discurso.

No cerne dessa discussão também está a centralidade dos indicadores e o modo como são empregados via avaliação externa, provas estandardizadas, evidenciando o predomínio de uma racionalidade instrumental nas políticas públicas para educação. Indicadores sintéticos como o IDEPE podem emitir mensagens políticas equivocadas e pouco robustas, se forem mal interpretados. A visão geral do resultado de um indicador sintético também pode induzir políticos a tomar decisões simplistas, que, se combinadas a outras observações de aspectos sociais, propiciaria conclusões políticas mais sofisticadas.

\section{REFERENNCIAS}

BALL, S. Sociologia das políticas educacionais e pesquisa crítico-social: uma revisão pessoal das políticas educacionais e da pesquisa em política educacional. Currículo sem Fronteiras, n.2, v.6, p.10-32, jul./dez. 2006. Disponível em: $<$ www.curriculosemfronteiras.org>. Acesso em: 12 de jun. 2010.

CENTRO LATINO AMERICANO DE ADMINISTRAÇÃO PARA O DESENVOLVIMENTO. Uma nova gestão pública para a América Latina. 1998. Disponível em < http:www.bresserwesite.org.br>. Acesso em: 15 jul. 2008.

COSTA, M. O . Contrarreformas, Nova Gestão Pública e relações públicoprivadas: mapeando conceitos, tendências e influências na educação. Revista Brasileira de Política e Administração da Educação. V. 35, n. 1, p. 159 -179, jan. abr., 2019.

DARDOT, P.; LAVAL. C. A nova razão do mundo: ensaio sobre a sociedade neoliberal. São Paulo: Boitempo, 2016. 
DASSO JUNIOR, A. E. "Nova gestão pública: a teoria da administração pública do estado ultraliberal". 2014. Disponível em: <htpp://www. publicadireito.com.br/artigos/?cod=d05c25e6e6c5d489>. Acesso em: 08 mar. 2018.

DOURADO, L. F.; OLIVEIRA, J. F. A qualidade da educação: perspectivas e desafios. Caderno CEDES. Campinas, v. 29, n. 78, p. 201-215, maio-ago., 2009.

FUNDAJ - Fundação Joaquim Nabuco. Avaliação do plano de ações articuladas (PAR) no contexto do plano de metas compromisso todos pela educação. Relatório de Pesquisa. Recife: ago., 2009.

LACLAU, E.; MOUFFE, C. Hegemony and socialist strategy. London: Verso, 1985.

LACLAU, E. Os novos movimentos sociais e a pluralidade social. RBCS. n.2, vol.1, p. 41-47, out. 1986.

. Nuevas reflexiones sobre la revolución de nuestro tempo. Buenos Aires: Ediciones Nueva Visión, 1993.

. Sujeito da política, política do sujeito. Política hoje. Recife: ano 4, n.2, p. 09 -28, jan-jun, 1997.

MENDONÇA, D. de; RODRIGUES, L. P. R. (Orgs.). Pós-estruturalismo e teoria do discurso: em torno de Ernesto Laclau. $2^{\mathrm{a}}$ ed. Porto Alegre: EDIPUCRS, 2014.

- Do estruturalismo ao pós-estruturalismo: entre fundamentar e desfundamentar. In: MENDONÇA, D. de; RODRIGUES, L. P. R. (Orgs.). Pósestruturalismo e teoria do discurso: em torno de Ernesto Laclau. $2^{\mathrm{a}}$ ed. Porto Alegre: EDIPUCRS, 2014.

MOUFFE, Chantal. O regresso do político. Lisboa: Gradiva, 1996.

OLIVEIRA, D. A. A nova gestão pública no contexto escolar e o dilema dos (as) diretores (as). Revista Brasileira de Política e Administração da Educação. v. 33, n. 3, p. 707-726, set.-dez., 2017. 
OLIVEIRA R. M. Da universalização do ensino fundamental ao desafio da qualidade: uma análise histórica. Educação e Sociedade. Campinas, v. 28, n. 100, p. 661-690. out. 2007.

Nova gestão pública e governos democráticos populares: contradições entre a busca da eficiência e a ampliação do direito à educação. Educação e Sociedade. Campinas, v. 36, n. 132, p. 625- 646, jul.-set., 2015.

PERNAMBUCO. Lei $\mathrm{n}^{\circ}$ 15.377, de 16 de setembro de 2014. Estabelece as diretrizes orçamentárias do estado de Pernambuco para o exercício de 2015, nos

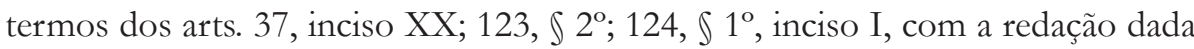
pela EC no 31, de 2008; e 131, da Constituição do estado de Pernambuco, e dá outras providências. Diário Oficial do Estado de Pernambuco, 17 set. 2014.

- Secretaria de Educação de Pernambuco. Secretaria de Educação Construindo a excelência em gestão escolar: curso de aperfeiçoamento: Módulo XII - Políticas de responsabilização educacional / Secretaria de Educação. - Recife: SEE, 2012.

.Secretaria de Educação de Pernambuco. Governo lança Projeto de Modernização Pública do Estado de Pernambuco. Recife: 27 de novembro de 2011.

Secretaria de Educação de Pernambuco. Programa de Modernização da Gestão Pública: metas para a educação. Recife: SEE, 2008.

VIEIRA, J. A.; FERRAZ, J. A. Percursos e avanços do tex to multimodal:novas perspectivas na contemporaneidade. Discursos Contemporâneos em Estudo, Brasília, v. 1, n. 1, 2012.

VERGER, A. Nueva gestión pública e educacion: elementos teóricos y conceptuales para el estúdio de um modelo de reforma educativa global. Educação e Sociedade. Campinas, v. 36, n. 132, p. 625- 646, jul. - set., 2015. 
LUCIANA ROSA MARQUES é Mestre em Educação e Doutora em Sociologia pela Universidade Federal de Pernambuco. É professora do Departamento de Administração Escolar e Planejamento Educacional e do Núcleo de Pesquisa em Política Educacional, Planejamento e Gestão da Educação, do Programa de PósGraduação em Educação da UFPE. E-mail: lmarques66@gmail.com

JULIANA CAMILA BARBOSA MENDES é Mestre em Educação pelo Programa de Pós-Graduação em Educação, Cultura e Comunicação em Periferias Urbanas da Universidade do Estado do Rio de Janeiro. Doutora em Educação pelo Programa de Pós-Graduação em Educação da Universidade Federal de Pernambuco. Email: julianacamila83@gmail.com

ORCID: https://orcid.org/0000-0002-4907-5658

IÁGRICI MARIA DE LIMA MARANHÃO é Mestre e Doutora em Educação pelo Programa de Pós-Graduação em Educação da Universidade Federal de Pernambuco. Professora da Faculdade Anchieta e da Uninassau. E-mail: iagricilimaster@gmail.com

ORCID: https://orcid.org/0000-0003-0492-8394 